\title{
Hemorrhagic Fever Epidemic in Grenada in the 18th Century: A Medical and Historical Analysis
}

\author{
Richard M. Kabuusu ${ }^{1,2 *}$, David Lennon ${ }^{2,3}$ \\ ${ }^{1}$ Department of Pathobiology, School of Veterinary Medicine, St. George's University, St. George's, Grenada \\ ${ }^{2}$ Graduate Studies Program, George's University, St. George's, Grenada \\ ${ }^{3}$ Department of Microbiology, School of Medicine, George's University, St. George's, Grenada \\ Email: ${ }^{*}$ rkabuusu@sgu.edu
}

Received 23 June 2014; revised 18 July 2014; accepted 5 August 2014

Copyright (C) 2014 by authors and Scientific Research Publishing Inc.

This work is licensed under the Creative Commons Attribution International License (CC BY).

http://creativecommons.org/licenses/by/4.0/

(c) (i) Open Access

\begin{abstract}
Unlike present times, when the major health concerns for Grenada are chronic diseases, the island's main health problems in the past were infectious diseases. The aim of this review is to examine whether a hemorrhagic fever epidemic precisely occurred in Grenada in the 1700s, and to identify the mostly likely etiologic agents associated with the outbreak. The methods used to collect information included museum research, interviewing a key informant and reviewing past documents in national archives in London, textbooks, and the internet. This medical and historical analysis reveals that there is sufficient evidence that an outbreak of hemorrhagic fever occurred in Grenada in 1700s and that there are more probable etiologies than previously thought. These include yellow fever, leptospirosis, viral hemorrhagic fever, and dengue hemorrhagic fever.
\end{abstract}

\section{Keywords}

Medical, Historical, Hemorrhagic Fever, Epidemic, Grenada, 18th Century

\section{Introduction}

Epidemics of infectious diseases have occurred since ancient times. Historically in Europe, infectious diseases such Black Death, measles, smallpox, syphilis and cholera led to massive loss of human lives (Karlen, 1996; Scott et al., 2001). In the Americas, outbreaks of infectious diseases including syphilis, influenza, typhus fever,

\footnotetext{
*Corresponding author.
} 
smallpox, measles, bubonic plague, diphtheria, cholera, scarlet fever, chicken pox, yellow fever, whooping cough and hemorrhagic fever have been reported since Christopher Columbus arrived (Phillips et al., 1992; Acuna-Soto et al., 2000).

Hemorrhagic fevers initially manifest as fever and pain of joints, abdomen and musculo-skeletal system. Later massive internal and external bleedings in forms of petechians, ecchymoses, epistaxis, hematemesis, hematuria (hemoglobinuria) and melana develop in the infected person. Examples of diseases associated with hemorrhage include viral hemorrhagic fevers (VHFs) especially Ebola and Marburg viruses, Dengue hemorrhagic fever (DHF) and Yellow fever (YF). These hemorrhagic fevers are more prevalent in countries with tropical climates. Viral hemorrhagic fevers (VHFs) are some of the deadliest infectious diseases known. They are transmitted by the direct contact with fluids of an infected person or other primate and have a case fatality rate of approximately 50\%. On the other hand, DHF and Yellow fever are transmitted by arthropods and have a variable case fatality rate (Karlen, 1996; Murray et al., 2005).

Historically, some of the worst recorded outbreaks of hemorrhagic fevers are reported to have occurred in Mexico in 1545 and 1576 (Acuna-Soto et al., 2000; Acuna-Soto et al., 2002; Acuna-Soto et al., 2004). In 1793, an outbreak of a severe acute hemorrhagic fever of unknown origin claimed many lives in Grenada particularly around the Carenage following the docking of Trans-Atlantic Slave ship "Hankey" (Cylde, 1985; Benson et al., 1988; Jessamy, 2008). Recently, outbreaks of hemorrhagic fevers have been recorded in Uganda, Democratic Republic of Congo and Sudan (CDC, 1995).

The exiting literature points to Yellow fever as the potential cause for the hemorrhagic fever epidemic in Grenada in 1700s. However, there are many other diseases now which are consistent with the clinical signs and epidemiological characteristics of the hemorrhagic fever outbreak observed in Grenada in 1700s. The purpose of this study is to use the medical and historical events to identify other possible etiologic agents that might have been responsible for this epidemic in Grenada in 1700s.

\section{Methods}

Ethical clearance was not sought because primarily this was a retrospective study that relied heavily on reviewing data. A key-informant was identified and interviewed by telephone (Anon, 2008a). Other major sources of information included historical documents in the Grenada public library, the British colonial library and the internet (Rossi et al., 1999). At the National Museum of Grenada, records of historical events were thoroughly examined, and antiquities were observed. Historical data was obtained on events such as traveling (sailing), Trans-Atlantic slave ships and conditions according to the season of the year whereas; medical data was obtained on incubation period of disease, symptoms (or clinical signs) of the disease, population structure affected and response to treatment protocols of the time. Information was also obtained on the contents of the slave ships, including the type of plants, animals and the personal belongings of the slaves. Medical and historical data were then correlated to establish a list of the most plausible differential diagnoses.

\section{Results}

\subsection{Historical Events}

Slaves were subjected to a careful medical examination by surgeons of the slave ship at the port of embarkation. Slaves with severe or obvious clinical disease were eliminated but, some sick slaves still boarded the slave-ships and these were often sold cheaper than the healthy ones (Newton, 1962). Slave ships were characterized by unhygienic environment, overcrowding, insufficient ventilation, the presence of decaying bodies in the slave ships, plants and animals, especially monkeys and rats (Newton, 1962; Karlen, 1996; Benson et al., 1988). Men, especially officers, were allowed to forcibly have sexual intercourse with female slaves during their transportation (Newton, 1962). Compared to other regions in Grenada at the time, the Carenage was enclosed, swampy and very crowded (Anon, 2008a; Jessamy, 2008).

\subsection{Characteristics of Persons Affected with the Hemorrhagic Fever}

Higher rates of severe disease were reported among persons who had recently arrived from Europe, particularly among those without prior exposure to warm climates when compared to the local inhabitants of Grenada. 
Among Europeans, the morbidity rate was as high as $70 \%$ but the mortality rate was $20 \%$. Persons aged between 15 - 50 years were most susceptible, and these young adult men also shared decks with slaves at night (Cylde, 1985; Jessamy, 2008). Residents of the Carenage were more affected than any other area in Grenada, and a lower prevalence of the disease occurred among indigenous plantation workers (Cylde, 1985; Jessamy, 2008; Anon, 2008a; Anon, 2008b).

\subsection{The Disease}

The disease exhibited an incubation period of about 3 days. It was a highly communicable disease, affecting any person who interacted closely with an infected individual, including family members, friends, sailors, as well as business and sexual partners. The spread of the disease to other Caribbean islands and other parts of the world such as the USA may be associated with the movement of ships containing infected persons and/or material. The disease pattern was not influenced by season. Patients presented with pale or yellow mucus membranes and skin (jaundice), hemoglobinuria and sometimes with a bloody vomitus (Cylde, 1985; Garret, 1994; Anon, 2008c).

\subsection{The Etiologic Agent}

The causative agent was highly virulent and was resistant to both the smell and smoke of coal tar as well as to Camphor. The etiologic agent did not respond to treatment with quinine that was obtained from the bark of Cinchona trees, but the organism was susceptible to Mercury (Chisholm, 1800).

\section{Discussion}

Vector-borne diseases are transmitted by many arthropods but more especially by mosquitoes and ticks. Malaria, transmitted by female anopheles mosquitoes, and yellow and dengue fevers, transmitted by Aedesegyptiae mosquito are vector-borne diseases that have been reported in the Caribbean. It is believed that these vector-borne disease and their vectors originated in Africa and were introduced to the Caribbean by trans-Atlantic movement of slave ships (Karlen, 1996; Diamond, 1999).

Our first rule out of possible differential diagnoses is malaria. Although severe falciparum malaria is capable of causing jaundice and bleeding disorders, Dr. Dacre reported that the hemorrhagic fever outbreak occurred during the winter, and that it was not highly prevalent in low swampy areas (Cylde, 1985). We now know that Grenada has tropical climate and mosquitoes can spread the infection at any time of the year, but with a higher probability during the rainy seasons. The justification for ruling out malaria as a possible cause for the hemorrhagic fever outbreak is that it did not respond to treatment with the bark of Cinchoma, which was the treatment of choice for malaria at the time. Perhaps the method of administration of Cinchoma was not appropriate, given that Quinine that is obtained from Cinchoma has been an effective chemotherapeutic agent against malaria in recent times (Garret, 1994). Additionally, the vectors of the malaria protozoa were present in Grenada until the1950s when they were eliminated with dichlorodiphenyltrichloroethane (DDT) (Garret, 1994).

Yellow fever (YF) probably originated in East Africa, where it was known as, kidengapepo literally meaning, "sudden overtaking by a spirit." The Spanish translation of denga is dengue and this is somewhat confusing, as it is different to dengue (Jessamy, 2008). Yellow fever, with both human and animal hosts, has been the only preferred diagnosis of the 1700s hemorrhagic fever outbreak in Grenada by previous researchers (Cylde, 1985; Garret, 1994). Monkeys, including Cercopithecus mona were introduced to Grenada, from West Africa are a reservoir for Flavivirus, the etiologic agent for YF. In West Africa, Aedesaegyptiae is the vector which spreads YF from monkey-to-monkey, monkeys-to-humans and humans-to-humans (Benson et al., 1988). Many adult persons in West Africa were immune to yellow fever because it was endemic on the West African coast (Garret, 1994).

As is the case with yellow fever, Dengue hemorrhagic fever (DHF) may have been introduced into Caribbean, Grenada inclusive from Africa by methods similar to those which introduced Yellow fever, that is movement of slaves and ships (Karlen, 1996). In parts of Africa, the disease is maintained in the enzootic monkey-mosquitoes complex. In Grenada, the low monkey population coupled by persons invading mosquito habitats through the construction of houses for settlement meant that human beings may have provided an alternative host to other primates.

Transmission patterns of the hemorrhagic fever epidemic in Grenada in 1700s do not support arthropod-borne 
diseases but, are rather consistent with those diseases spread by very close contact with infected persons or animals. This recognition places arthropod-borne diseases such as Yellow fever, DHF and Malaria at the bottom of the list of differential diagnosis hemorrhagic fever epidemic in Grenada in 1700s. Yellow fever is a differential diagnosis only on the basis of the clinical signs (intoxication phase) observed by Dr. Chisholm. Yellow fever presents as liver failure (jaundice), kidney failure and massive gastrointestinal hemorrhage (Murray et al., 2005). Dengue fever causes bleeding in the form of petechiations and epistaxis by increasing vascular permeability (Benson, 1990).

The observation that this hemorrhagic fever was more prevalent among persons aged 15 - 50 years is closely associated with the nature of the economic activities of this age group at the time, which included guarding and cleaning the ship. While on the ships, these young adult men may have come in direct contact with contaminated urine from infected rats and other wild animals aboard slave ships that were meant for food or other use (Cylde, 1985). This method of disease transmission is highly suggestive of Leptospirosis (Weil's disease), an occupational hazard, which is characterized by jaundice, renal failure, hepatitis hemorrhage into the skin and mucus membranes and is caused by Leptospira interrogans icterohemorrhagiae (Benson, 1990). Dr. Chisholm reported success against the disease when he treated it with Mercury. Mercury was the treatment of choice for Leptospirosis, syphilis, gonorrhea and many skin diseases (Magner, 1992). Additionally, recent studies in Grenada have shown that rats are seropositive for serovars of the icterohemorrhagiae serogroup (Keenen et al., 2009). This evidence does not only provide further support for the inclusion of Leptospirosis but, also places it as the mostly likely diagnosis for this outbreak.

The observation that hemorrhagic fever selectively and severely affected Europeans may indicate that the disease originated in Africa. VHFs are included in the differential diagnosis because the mode of transmission indicates that there was direct contact with infected person or primate; the causative organism was highly virulent and multiple organ systems were involved as is evidenced by hematemesis (gut), jaundice (liver) and hemoglobinuria (kidney). VHFs are zoonotic infections and are transmitted by direct contact with infected monkeys and persons (Karlen, 1996; Murray et al., 2005). People of African descent including slaves and local inhabitants, were more resistant to the etiologic agent, and recent studies have shown that about $3 \%$ and $18 \%$ of the central African population are seropositive for Marburg and Ebola viruses respectively (Gonzalez et al., 2000). Slaves who eventually died from the disease were those whose immunity had been compromised because of malnutrition, stress or other factors. A case fatality rate of $20 \%$ is much lower than what is usually associated with Ebola but, it could be due to underreporting as a result of the acuteness of the disease.

A limitation to this study is that some of the documents about the history of Grenada prior to 1764 were lost with the burning down of the governor's residence in 1792 (Jessamy, 2008). This prevented a thorough analysis of events that culminated into the outbreak of the hemorrhagic fever. The clinical presentation of persons with the disease is also not explicit and therefore only a differential diagnosis can be made. Besides monkeys, other animals that were probably on the ships are not mentioned in historical documents.

\section{Conclusion}

There is satisfactory evidence of an outbreak of a hemorrhagic fever, but most of the literature is biased towards yellow fever. As controversial as it may seem, the historical events, the clinical manifestation of the disease, the epidemiological characteristics, the disease transmission patterns, and properties of etiologic agent, are most supportive of Leptospirosis (Weil's disease). Other diseases including VHFs and DHF should still be considered until more evidence suggests otherwise. If it were possible, a definitive diagnosis could only be made using modern technology such as DNA analysis on parts of the dead victims.

\section{Acknowledgements}

We would like to thank Mr. Norbert Wasswa and Miss Evelyn Nantumb we for reviewing the documents at the British colonial library in London; Dr. Nicole Philip for her assistance in providing the necessary historical resources; and to Dr. Linda Stone for her assistance with anthropological information.

\section{References}

Acuna-Soto, R., Romero, L. C., \& Maguire, J. (2000). Large Epidemics of Hemorrhagic Fevers in Mexico 1545-1815. American Journal of Tropical Medicine and Health, 62, 733-739. 
Acuna-Soto, R., Stahle, D. W., Cleaveland, M. K., \& Therrell, M. D. (2002). Megadrought and Megadeath in 16th Century Mexico. Emerging Infectious Disease, 8, 360-362. http://dx.doi.org/10.3201/eid0804.010175

Acuna-Soto, R., Stahle, D. W., Therrell, R. D., Griffin, R. D., \& Cleaveland, M. K. (2004). When Half of the Population Died: The Epidemic of Hemorrhagic Fevers of 1576 in Mexico. FEMS Microbiology Letters, 1, 1-5.

http://dx.doi.org/10.1016/j.femsle.2004.09.011

Anon (2008a). Personal: Personal Interview.

Anon (2008b). National Museum of Grenada.

Anon (2008c). National Archives, London.

Benson, K., \& Glenn, A. M. (1988). Capture Techniques and Morphological Measurements of the Mona Monkey. Cercopithecus mona, on the Island of Grenada. American Journal of Physical Anthropology, 105, 481-491.

Benson, A. S. (1990). Control of Communicable Diseases in Man (15th ed.). Washington DC: American Public Health Association.

CDC (Centers for Disease Control) (1995). Outbreak of Ebola Viral Hemorrhagic Fever-Zaire, 1995. Morbidity and Mortality Weekly Report, 44, 381-382.

Chisholm, C. (1800). Malignant Pestilence Fever in Grenada in 1793. Medical Repository, 2, 268-274.

Cylde, D. F. (1985). Health in Grenada: A Social and Historical Account. London: Vade-Mecum Press.

Diamond, J. (1999). Guns, Germs, and Steel. New York: W. W. Norton \& Company Inc.

Garret, L. (1994). The Coming Plague. New York: Penguin Books.

Gonzalez, J. P., Nakoune, E., Slenczka, W., Vidal, P., \& Morvan, J. M. (2000). Ebola and Marburg Virus Antibody Prevalence in Selected Populations of the Central African Republic. Microbes and Infection, 2, 39-44.

Jessamy, M. (2008) A Case of Grenada. http://cavehill.uwi.edu/bnccde/grenada/conference/papers/jessamy.html

Karlen, A. (1996). Man and Microbes. Disease and Plagues in History and Modern Times. New York: Touchstone.

Keenen, J., Sharma, R., Dicker, R., Rayner, J., \& Stone, D. (2009). Seroprevalence of Leptospira in Rattusnorvegicus in Grenada, West Indies. West Indian Medical Journal, 58, 115-118.

Magner, L. N. (1992). A History of Medicine. New York: Marcel Dekker Inc.

Murray, P. R., Rosenthal, K. S., \& Pfaller, M. A. (2005). Medical Microbiology. Philadelphia, PA: Elsevier Mosby.

Newton, J. (1962). The Journal of a Slave Trader. London: The Epworth Press.

Phillips, W. D., \& Phillips, C. R. (1992). The Worlds' of Christopher Columbus. Cambridge: Cambridge University Press.

Rossi, P. H., Freeman, H. E., \& Lipsey, M. W. (1999). Evaluation: A Systematic Approach (6th ed.). Thousand Oaks, CA: Sage Publications Inc.

Scott, S., \& Duncan, C. J. (2001). Biology of Plagues: Evidence from Historical Populations. Cambridge \& New York: Cambridge University Press. http://dx.doi.org/10.1017/CBO9780511542527 
Scientific Research Publishing (SCIRP) is one of the largest Open Access journal publishers. It is currently publishing more than 200 open access, online, peer-reviewed journals covering a wide range of academic disciplines. SCIRP serves the worldwide academic communities and contributes to the progress and application of science with its publication.

Other selected journals from SCIRP are listed as below. Submit your manuscript to us via either submit@scirp.org or Online Submission Portal.
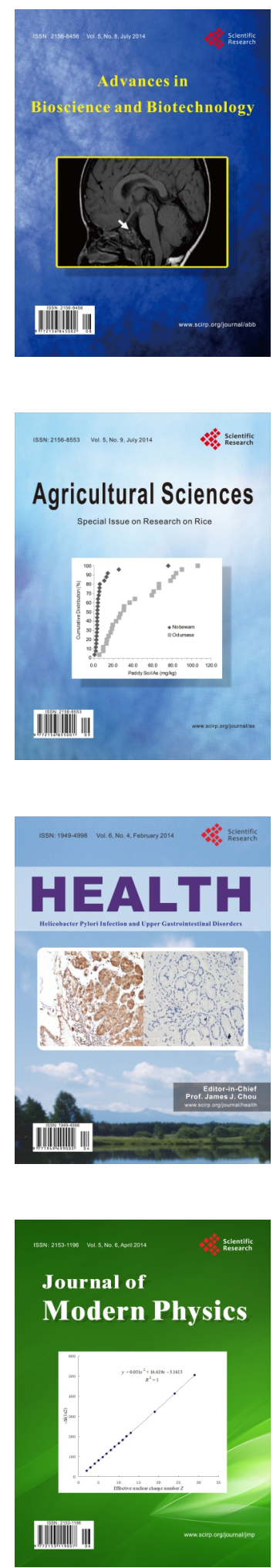
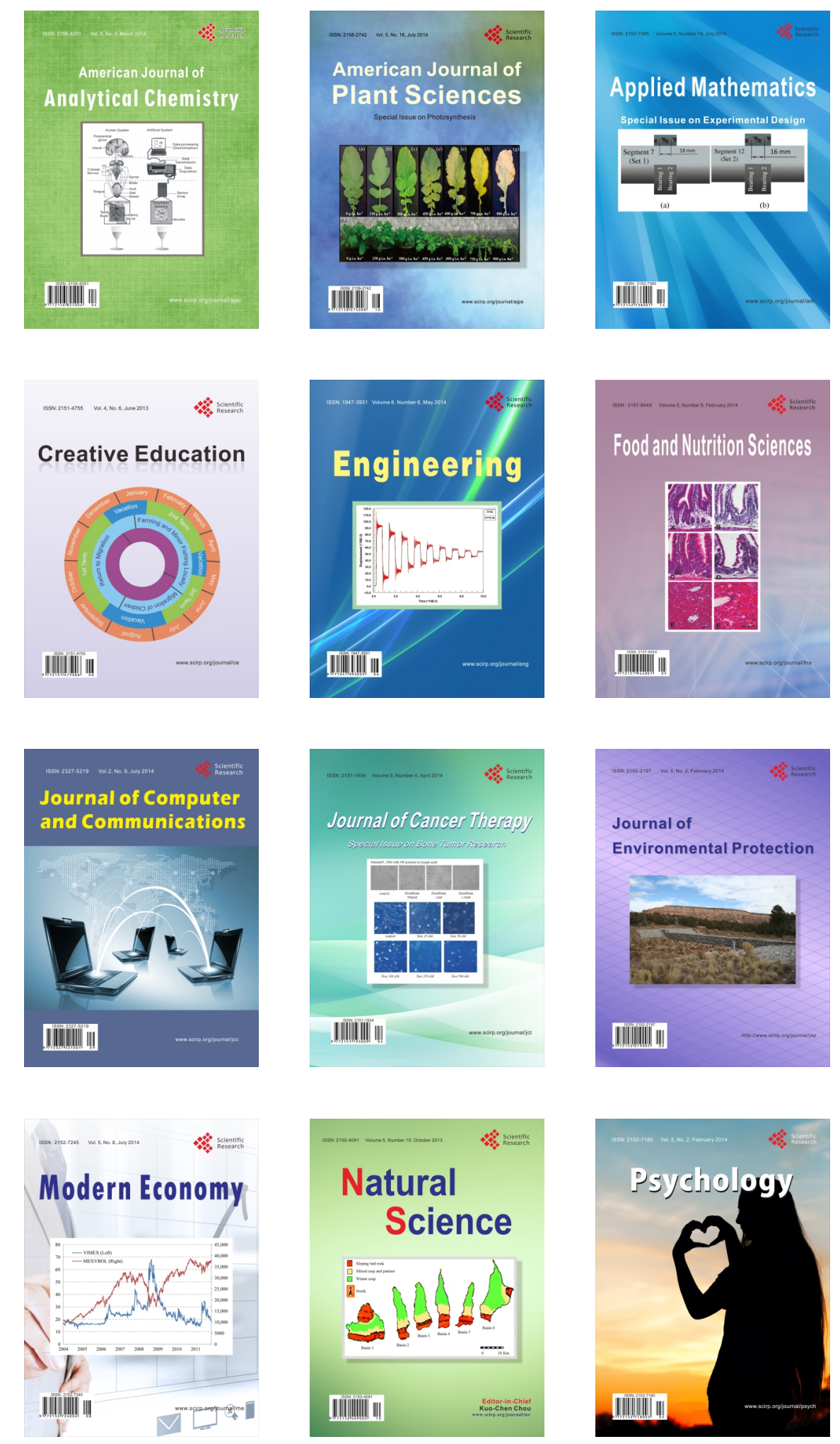